\title{
ANAEROBIC BIOPROCESSING OF LOW-RANK COALS
}

CONTRACT No.DE-AE22-90PC90051

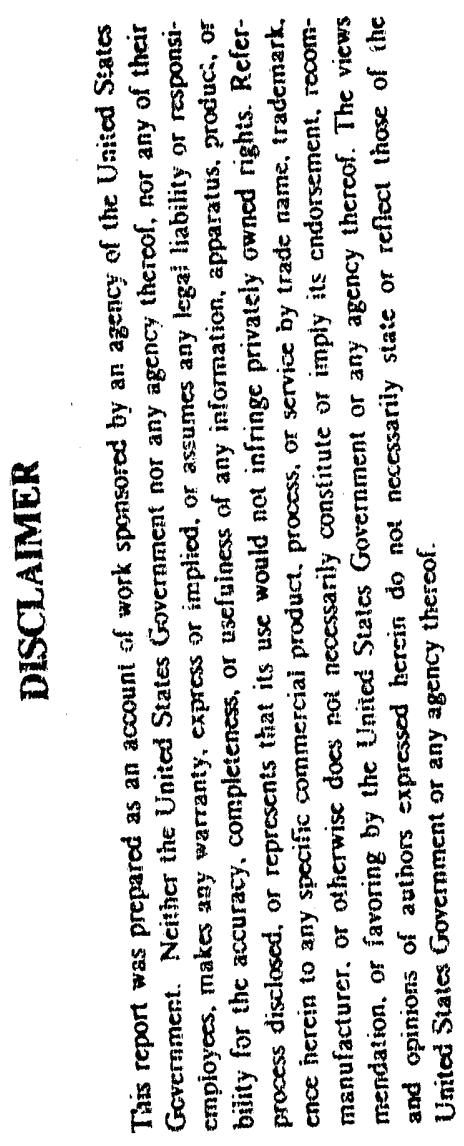

PROGRESS REPORT

April I - June 30, 1992

Mahendra K. Jain

Ramani Narayan

Ohantaek Han

Michigan Biotechnology Institute

3900 Collins Road

P.O. Box 27509

Lansing, Michigan 48909

MASIER 


\section{QUAR'TERLY PROGRESS REPORT}

Anaerobic Processing of Low-rank Coals

Contract No. DE-AC22-90PC90051

April 1 - June 30, 1992

\section{INTRODUCTION}

The overall goal of this project is to find biological methods to remove carboxylic functionalities from low-rank coals and to assess the properties of the modified coal towards coal liquefaction. The main objectives for this quarter were : (i) continuation of microbial consortia development and maintenance, (ii) evaluation of commercial decarboxylase, (iii) decarboxylation of lignite, demineralized Wyodak coal and model polymer, and (iv) characterization of biotreated coals.

\section{QUARTERLY PROGRESS SUMMARY}

- Two batch fermentor systems were completed and three other fermentors under optimum conditions for coal decarboxylation are in progress

- Inhibition of growth of methanogens in the batch fermertor system enhanced the carbon dioxide production.

- Adapted microbial consortium produced more gas from lignite than Wyodak subbituminous coal

- Phenylalanine decarboxylase exhibited insignificant coal decarboxylation activity.

- Two different microbial consortia developed on coal seem to be effective in decarboxylation of a polymer containing free carboxylic groups.

- CHN analyses of additional biotreated coals reconfirm increase in $\mathrm{H} / \mathrm{C}$ ratio by $3-6 \%$.

\section{PROGRESS REPORT}

\section{Continue Coal Decarboxylation in Batch Fermentors and Development of Microbial Consortia}

\section{Batch Fermentor Systems}

Since two batch fermentor systems (\#13 and \#14) inoculated with microbial consortium LC were completed, three new batch fermentor systems containing consortium RW were initiated under presumptive optimum conditions for coal decarboxylation (Table 1). The optimum conditions were presumed on the basis of previously run batch systems. Microbial consortium RW seems to be potentially a good culture consortium because of its stability during the maintenance/ 
Table 1. Main parameters for coal decarboxylation in batch fermentor systems (\#16-\#18)

\begin{tabular}{|c|c|c|}
\hline Batch No. & Gas phase & Antimethanogenic agent \\
\hline$\# 16$ & Nitrogen & No \\
\hline$\# 17$ & Nitrogen & Yes \\
\hline$\# 18$ & $\begin{array}{c}5 \% \text { Hydrogen }+95 \% \\
\text { Nitrogen }\end{array}$ & No \\
\hline
\end{tabular}

subculturing over 16 months and reproducible coal decarboxylation results. Hydrogen gas at $5 \%$ is used in fermentor \#18 since our previous observations (quarterly reports, 12/1991 and 3/1992) indicated that the bioprocessing of coal under hydrogen gas phase resulted in coal products with higher $\mathrm{H} / \mathrm{C}$ ratio. Antimethanogenic agent(2-bromoethane sulfonic acid) is being used in batch fermentor \#17 to inhibit methanogenic bacteria which may also result in higher H/C ratio of coal. Methane content in the exit gas of each fermentor is being analyzed by GC to monitor the activity of methancgens during coal biotreatment. As presented in Figure 1, the total carbon dioxide production on day 35 was 11,28 , and 16 mmoles from \#16, \#17, and \#18 batch systems, respectively. As expected, fermentor \#17 containing antimethanogenic agent gave the highest carbon dioxide production probably due to inhibition of further conversion of carbon dioxide to methane gas. Increased amounts of carbon dioxide were also obtained when coal was anaerobically biotreated under $\mathrm{H}_{2}$ gas phase systern (fermentor \#18) than under $\mathrm{N}_{2}$ gas phase (fermentor \#16). Highest methane concentration was detected in the exit gas from fermentor \#16 during the first week of biotreatment period, whereas low levels of methane were detected in the exit gas from fermentor \#18. No methane gas was detected from fermentor \#17, indicating complete inhibition of methanogenic bacteria by 2-bromoethane sulfonic acid. These batch systems will be terminated on day 49 and coal characterization will be followed.

2. Decarboxylation of coal in the absence of methanogens

Microbial consortium RW9 was subcultured in the presence of antimethanogenic agent to examine the effect of the absence of methanogenic activity on coal decarboxylation. The first and second subcultures of decarboxylating consortia grown on $5 \%$ coal produced $3-4 \%$ more carbon dioxide than controls without coal. The microbial consortium LC6 was also subcultured in the presence of antimethanogenic agent. The first LC subculture also exhibited $6-7 \%$ more carbon dioxide production from coal than controls. However, as subculturing continued, there was a decrease in net carbon dioxide production from coal. The reasons for decrease in net carbon dioxide production are not clear at this stage. 


\section{I1. Enzyme Study}

Our preliminary crude enzyme study showed that the decarboxylase(s) present in the microbial consortia that decarboxylates coal may be extracellular in nature (refer to quarterly report, 3/92). Therefore, attempts were made to investigate the coal decarboxylation potential of commercially available decarboxylase enzyrne. First of all, phenylalanine decarboxylase was examined for coal decarboxylation. Enzymatic activity was assayed by GC measuring carbon dioxide in the head space of the reaction vial. The final concentrations of phenylalanime, pyridoxal phosphate, coal, and enzyme were $1.6 \times 10^{-2} \mathrm{M}, 7 \times 10^{-5} \mathrm{M}, 33.3 \mathrm{mg} / \mathrm{ml}$ and $5 \mathrm{mg} / \mathrm{ml}$, respectively. The enzyme reaction mixture was incubated at $37^{\circ} \mathrm{C}$. The $\mathrm{pH}$ was maintained at 5.5 using $0.09 \mathrm{M}$ succinate buffer solution. The data as presented in Table 2 , indicate that no coal decarboxylation activity was observed in a short incubation time, whereas low activity was detected at $16 \mathrm{hr}$.

Table 2. Coal decarboxylation using phenylalanine decarboxylase (Unit: \% carbon dioxide in the headspace of reaction vial)

\begin{tabular}{|c|c|c|c|c|}
\hline Reaction time & $\begin{array}{c}\text { Control } \\
\text { (Enzyme only) }\end{array}$ & $\begin{array}{c}\text { Enzyme + } \\
\text { Phenylalanine }\end{array}$ & Enzyme + Coal & $\begin{array}{c}\text { Net } \mathrm{CO}_{2} \\
\text { production } \\
\text { from coal }\end{array}$ \\
\hline $10 \mathrm{~min}$ & 0.16 & 0.99 & 0.14 & -0.02 \\
\hline $30 \mathrm{~min}$ & 0.20 & 2.03 & 0.20 & 0 \\
\hline $60 \mathrm{~min}$ & 0.20 & 4.11 & Not determined & - \\
\hline $16 \mathrm{hr}$ & 4.04 & 8.91 & 4.35 & 0.31 \\
\hline $72 \mathrm{hr}$ & 18.91 & 23.92 & 1.5 .82 & -3.09 \\
\hline
\end{tabular}

\section{Decarboxylation of Modified Coal and Polymers}

1. Decarboxylation of Beulah Lignite

Decarboxylation of Beulah lignite was examined using the microbial consortium RW9 which was developed and adapted on Wyodak subbituminous coal. As presented in Figure 2, the profiles of gas production from two low-rank coals were nearly identical during the first 2.1 days, but after 21 days lignite exhibited rapid increase in gas production, mainly due to methane production. On day 42 , lignite produced about 0.4 atm more gas production than subbituminous coal. These results have shown that the consortium $R W 9$ is effective in removing oxygen from other low rank coals such as Beullah lignite.

2. Decarboxylation of Demineralized Coal

Demineralized coal obtained from Dr. Serio (Advanced Fuel Research, East Hartford, CN) was 
examined for decarboxylation using two different microbial consortia (RW9 and LC5). Demineralized coal showed higher gas production with consortium RW9 than consortium LC5 (Figure 3). However, in comparison to control (total gas production, $0.8-1.0 \mathrm{~atm}$ on day 42), 60$80 \%$ reduction in gas production was observed with demineralized coal. The $\mathrm{pH}(6.2-6.3)$ of culture media containing demineralized coal was lower than the pH (6.8-7.1) of untreated coal. Since demineralized coal contains high levels of free-COOH groups, it can reduce the buffering capacity of culture medium, resulting in $\mathrm{pH}$ shift of the medium. Methanogens are known to $b$ : sensitive to low $\mathrm{pH}$ (ca. pH 6), therefore, low medium $\mathrm{pH}$ due to demineralized coal might have caused severe reduction in $\mathrm{CH}_{4}$ production. Other possible explanation may be lack of some essential metal ions and trace elements in demineralized coal for growth of certain bacteria in microbial consortium. Decarboxylated coals (demineralized and control) will be analyzed for reduction in - $\mathrm{COOH}$ groups using a pyrolysis-FTIR method (courtesy: Dr. Serio, Advanced Fuel Research.).

\section{Model Polymers}

Initial attempts using unmodified model polymers were not successful because the total gas production from cultures containirg polymer was less than control. One of the reasons could be high initial concentration of polyacrylic acid and poly (methyl methacrylate) at 5\%. The data presented in Figure 4 indicate that consortium RW9 resulted in higher gas production from poly (acrylic acid) than poly (methyl methacrylate), whereas consortium LC5 gave reverse results on both polymers. These observations suggest that each microbial consortium may have different decarboxylase specificity. Subsequently, in order to elucidate the coal decarboxylation mechanism(s) by anaerobic microbial consortium, PMMA was partially hydrolyzed as described elsewhere (Biermann and Narayan, Poiymer. 28: 2176-21'78). Partially hydrolyzed PMMA at $0.2 \%$ was inoculated with microbial consortia RW and LC and is currently being monitored for gas production from the polymer. On day 10 , consortium L6A showed highest net gas production from the polymer. This experiment will be terminated on day 35 and the decarboxylated polymer will be characterized for loss of carboxyl groups using titration and FT. IR methods.

\section{Characterization of coal}

\section{CHN analysis}

Wyodak subbituminous coals of different particle size were decarboxylated in batch configuration systems for 56 days where microbial consortium LC was used with $0.4 \%$ sodium lactate and $0.2 \%$ ammonium chloride. 100 mesh and 20 mesh Wyodak coals were used for \#13 and \#14 batch system, respectively. The biotreated coals were filtered, freeze-dried and stored at $-20{ }^{\circ} \mathrm{C}$ under argon atmosphere until analysis. The stored biotreated coals and control coals were vacuum-dried at $85^{\circ} \mathrm{C}$ overnight and analyzed for $\mathrm{CHN}$ content to determine $\mathrm{H} / \mathrm{C}$ ratio. The results (Table 3 ) indicate that $\mathrm{H} / \mathrm{C}$ ratio of $\# 13$ and $\$ 14$ biotreated coal samples was increased by $3.1 \%$ and $6.8 \%$, respectively. 
Table 3. Elemental analysis of biotreated coals from \#13 and \#14 fermentors

\begin{tabular}{|c|c|c|c|}
\hline Sample & $\% \mathrm{C}$ & $\% \mathrm{H}$ & H/C ratio \\
\hline $\begin{array}{c}100 \text { mesh } \\
\text { control coal }\end{array}$ & $66.90 \pm 0.44$ & $4.81 \pm 0.01$ & 0.863 \\
\hline $\begin{array}{c}\text { \#13 fermentor } \\
(100 \text { mesh coal })\end{array}$ & $63.07 \pm 0.06$ & $4.68 \pm 0.06$ & 0.890 \\
\hline $\begin{array}{c}20 \text { mesh } \\
\text { control coal }\end{array}$ & $62.85 \pm 2.07$ & $4.33 \pm 0.13$ & 0.827 \\
\hline $\begin{array}{c}\text { \#14 fermentor } \\
(20 \text { mesh coal })\end{array}$ & $59.78 \pm 0.18$ & $4.40 \pm 0.14$ & 0.883 \\
\hline
\end{tabular}

\section{Titration of $\mathrm{COOH}$ Groups}

We have just initiated confirmation of loss of $-\mathrm{COOH}$ groups in biotreated coals by a titration method (Blom et at. 1957, Chemical structure and properties of coal, Fuel. 36: 135-153). The method involved acid washing of coal to remove cations from carboxyl groups and then adding calcium acetate to chelate calcium ions with ionized carboxylic groups. The released acetic acid was titrated with $0.02 \mathrm{~N} \mathrm{NaOH}$ solution. This method may allow us to confirm our FT-IR results. Blom et al., however, pointed that this method may have some shortcomings due to limited accessibility of chemical agent to coal macromolecular structure and size effect of coal particles.

\section{SIGNIFICANT ACHIEVEMENTS}

1. Use of antimethanogenic agent increased carbon dioxide production from coal in the batch fermentor configuration

2. Coals biotreated in batch fermentor systems showed $3.1-6.8 \%$ increase in $\mathrm{H} / \mathrm{C}$ ratio.

3. Microbial consortia adapted on Wyodak coal also removed oxygen efficiently from lignite and demineralized Wyodak coal.

4. Microbial consortium adapted on coal seems to possess decarboxylase enzyme since the consortium was effective in decarboxylation of a model polymer. 


\section{OBJECTIVES FOR NEXT QUARTER}

1. Complete coal decarboxylation under the batch reactor system.

2. Complete preliminary polymer decarboxylation using coal adapted microbial consortia.

3. Complete characterization of biotreated coal.

4. Conduct microautoclave liquefaction of the biotreated coal.

5. Write final report 
Figure 1. Profiles of carbon dioxide production from batch fermentor systems (\#16-\#18) containing 100 mesh Wyodak coal
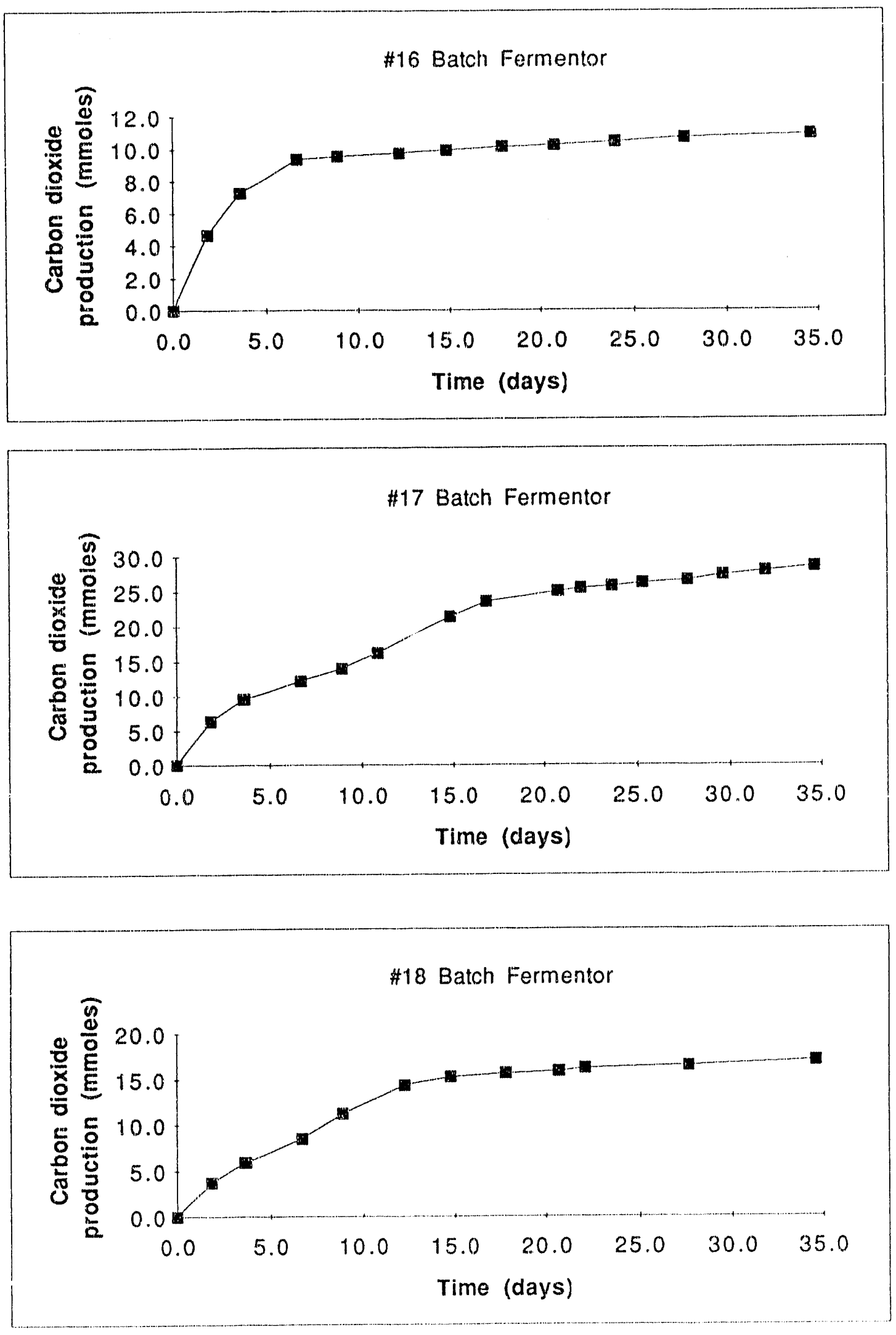
Figure 2. Gas producition profiles from Beulah lignite and Wyodak subbituminous coal by microbial consortium RW9

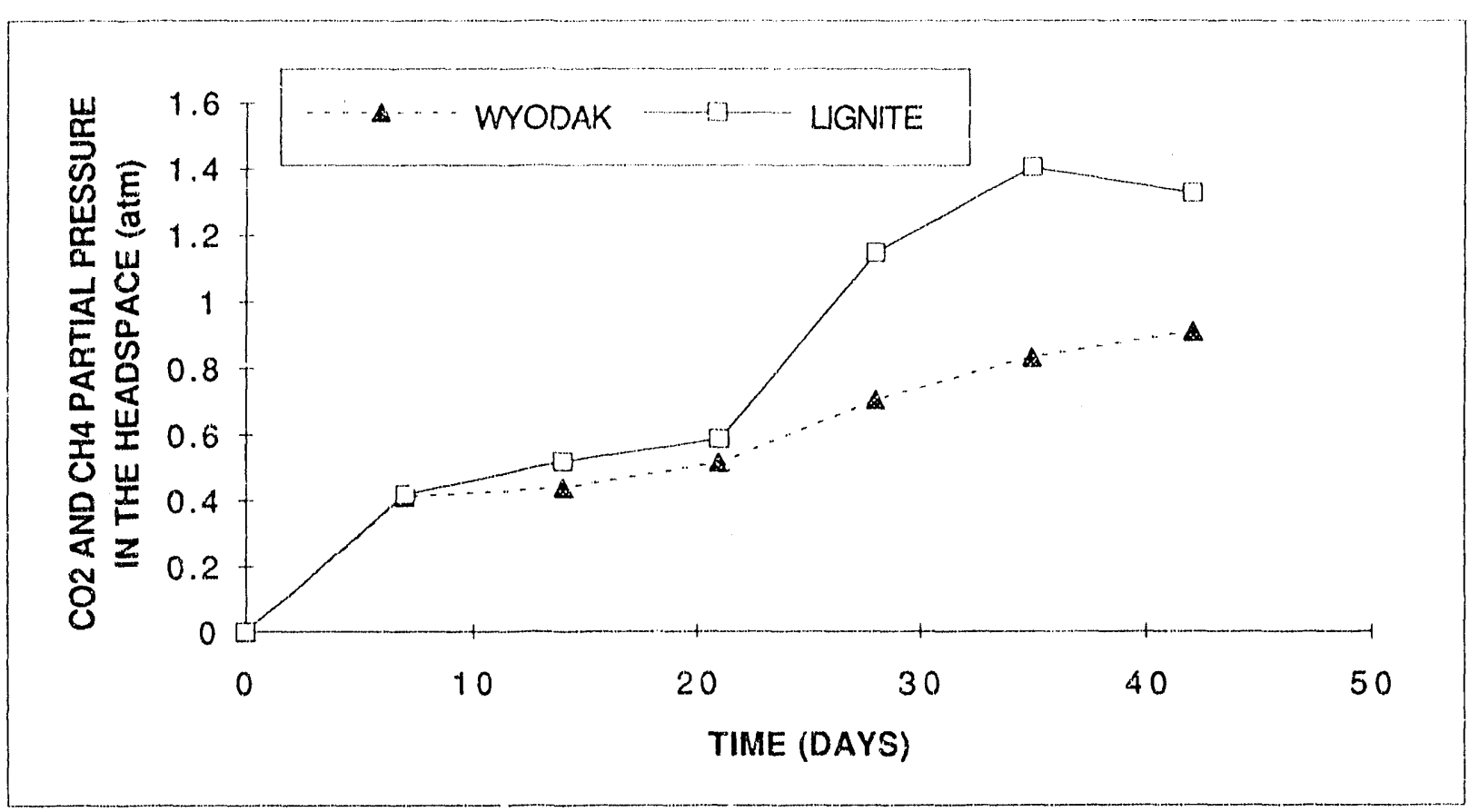

Figure 3. Gas production profiles from $5 \%$ demineralized Wyodak coal with two different microbial consortia

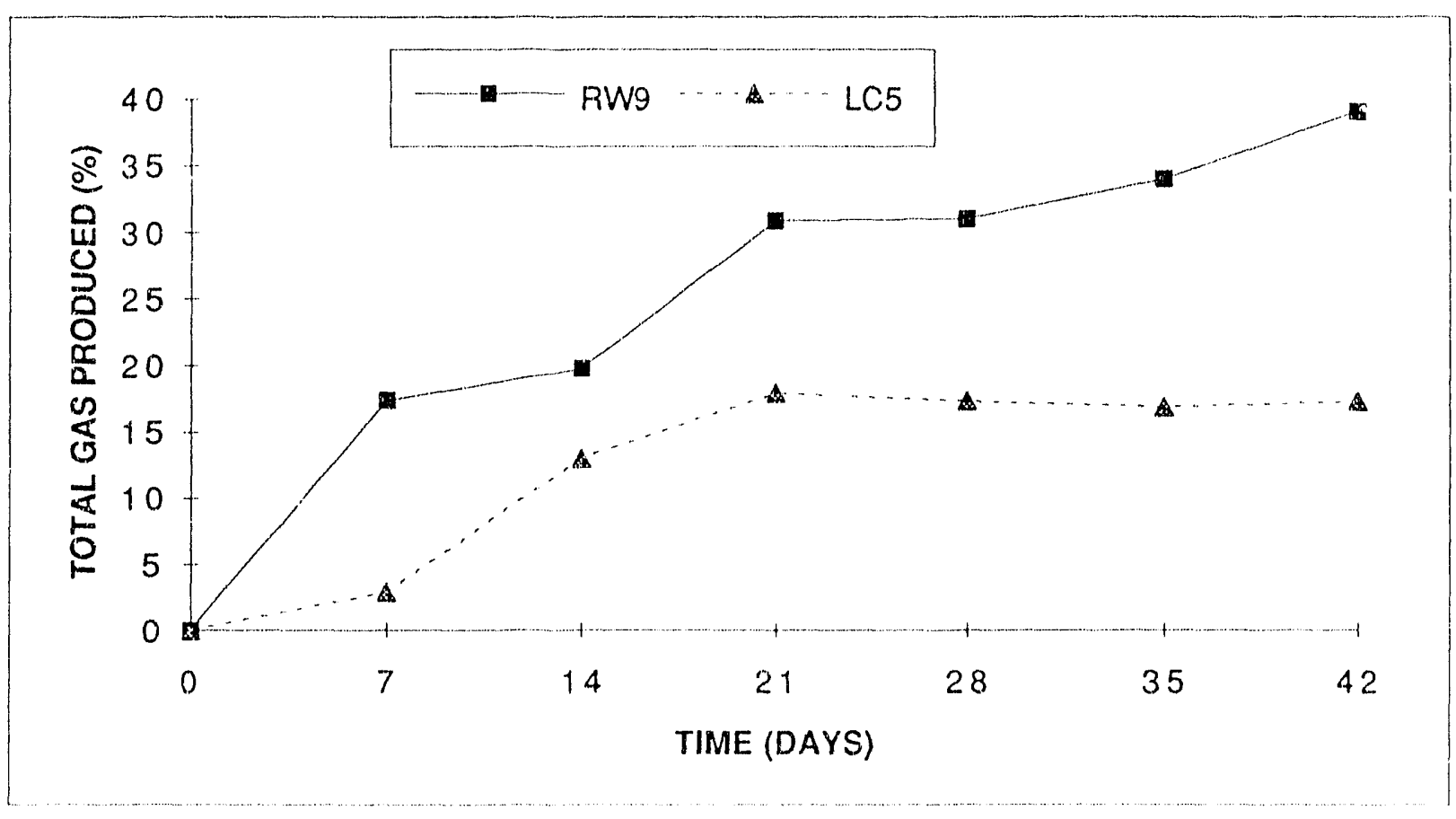


Figure 4. Gas production profiles from two model polymers $(+0.4 \%$ sodium succinate) inoculated with two different microbial consortia RW and LC
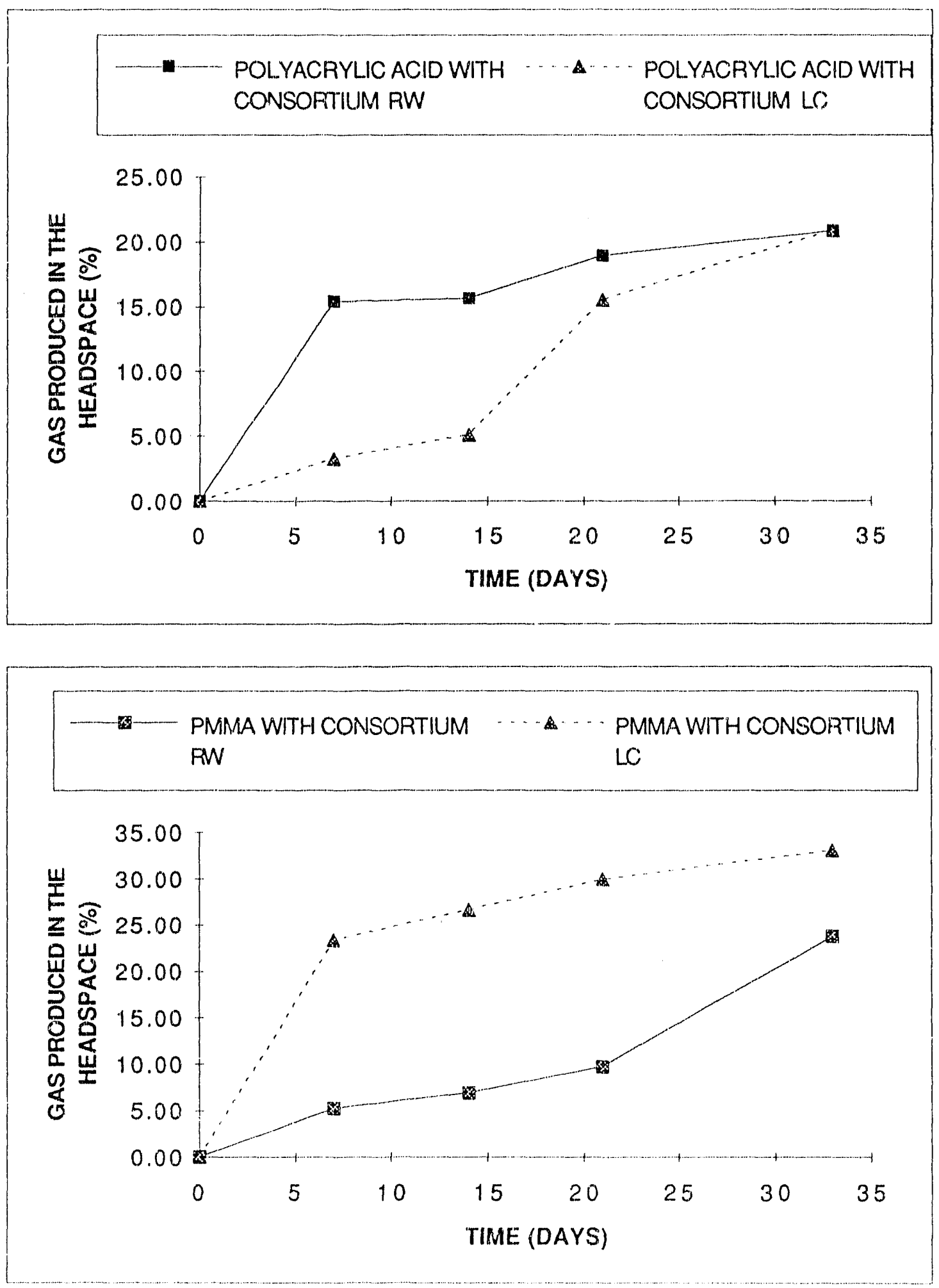

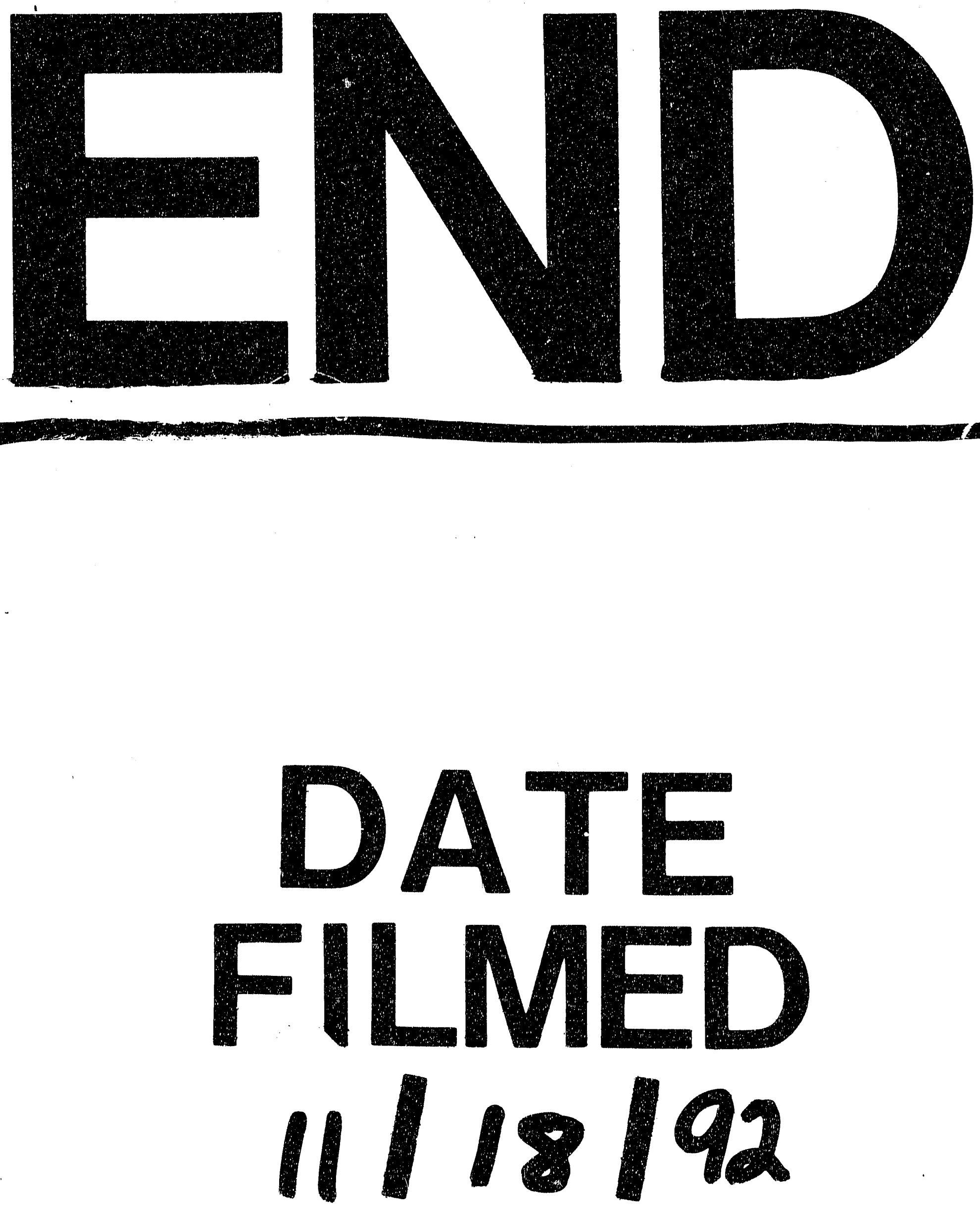
